\title{
Lokal ileri ve/veya lenf düğümü tutulumu olan rektum kanserinde neoadjuvan kemoradyoterapiye yanit ve sfinkter koruyucu cerrahinin araştırılması
}

\author{
Şükran Eskici Öztep', Eda Bengi Yılmaz², Mehmet Özgür Türkmenoğlu ${ }^{3}$ \\ ${ }^{1}$ Mersin Şehir Eğitim ve Araştırma Hastanesi, Radyasyon Onkolojisi, Mersin, Türkiye \\ ${ }^{2}$ Mersin Üniversitesi Tıp Fakültesi Radyasyon Onkolojisi Anabilim Dalı, Mersin, Türkiye \\ ${ }^{3}$ Mersin Üniversitesi Tıp Fakültesi Genel Cerrahi Anabilim Dalı, Mersin, Türkiye
}

$\ddot{0} \mathbf{z}$

Amaç: Lokal ileri ve/ veya lenf düğümü tutulumu olan rektum kanseri tanısıyla uzun dönem neoadjuvan kemoradyoterapi uygulanan olgularda tümör ve nodal evrede gerileme ve patolojik yanıt oranlarının belirlenmesi amaçlanmıştır. Yöntem: Mersin Şehir Eğitim ve Araştırma Hastanesi Radyasyon Onkolojisi Bölümünde 2017 yılı içerisinde neoadjuvan kemoradyoterapi uygulanmış olan lokal ileri ya da lenf dügümü metastazı olan rektum kanserli 23 olgunun verileri retrospektif olarak değerlendirildi. Tüm olgulara kemoterapi, radyoterapi ile eşzamanlı olarak uygulanmıştır. Yirmi bir olguya neoadjuvan kemoradyoterapi bitiminden 4- 8 hafta sonra küratif cerrahi yapılmıştır. Neoadjuvan kemoradyoterapiye yanıtın değerlendirmesi ameliyat öncesi evreleme ile patolojik evrenin karşılaştırılması ile yapıldı. Rezeksiyon materyalinde herhangi bir kanser hücresi gözlenmemesi patolojik tam yanıt olarak değerlendirildi. Tümör ve nodal evredeki gerileme kısmi yanıt olarak değerlendirildi. Bulgular: Olguların ortalama yaşı 57.3 9.8 idi. Tedavi öncesi yapılan radyolojik incelemelerde olguların 9'unda (\%39.1) T3, 14'ünde (\%60.9) T4 tümör saptandı. Olguların 14'ünde (\%60.9) lenf dügümü metastazı izlenmezken, 9 olguda (\%39.1) lenf düğümü metastazı saptandı. Tümörün yerleşim yeri; 8 (\%34.8) alt rektum, 7 (\%30.4) orta rektum, 8 (\%34.8) üst rektum idi. Sfinkter koruyucu cerrahi olguların \%71.4'üne uygulanabildi. Neoadjuvan kemoradyoterapi sonrası olguların 7'sinde (\%30.4) patolojik tam yanıt, 13'ünde (\%56.5) ise kısmi yanıt izlendi. Neoadjuvan tedaviye yanıt ile tümör yerleşimi ve sfinkter koruyucu cerrahi uygulanabilirliği arasında yapılan istatistiksel analizde anlamlı farklılık izlenmemiştir Sonuç: Neoadjuvan kemoradyoterapi uygulanan olguların büyük bir kısmında tümörde boyut ve/ veya evre gerilemesi sağlanabilmektedir. Evre gerilemesi, sfinkter koruyucu cerrahi uygulanabilirliğini arttırmamaktadır.

Anahtar sözcükler: Lokal ileri rektum kanseri, neoadjuvan kemoradyoterapi, sfinkter koruyucu cerrahi

Yazının geliş tarihi: 12.07.2018

Yazının Kabul tarihi:06.09.2018

Sorumlu Yazar : Şükran Eskici Öztep Mersin Şehir Eğitim ve Araştırma Hastanesi Radyasyon Onkolojisi, Mersin, Türkiye, E-Posta: dreskici@hotmail.com Tel: 03242251000 


\title{
Investigation of neoadjuvant chemoradiation response and sphincter saving surgery in locally advanced rectal cancer with or without lymph node metastasis
}

\begin{abstract}
Purpose: The aim of this study was to evaluate the response to neoadjuvant long course chemoradiotherapy for patients with locally advanced rectal cancer with or without lymph node metastasis. Methods: The data of 23 rectal cancer cases that had locally advanced with or without lymph node involvement treated with neoadjuvant chemoradiotherapy in Mersin City Training and Research Hospital Radiation Oncology Department in 2017 were evaluated retrospectively. All cases received concurrent chemoradiotherapy. Curative intend surgical resection was performed to 21 cases 4- 8 weeks after the completion of chemoradiotherapy. Response to neoadjuvant chemoradiotherapy was assessed by comparing the preoperative clinical staging and postoperative pathological evalation. Histopathological complete response was defined as no tumor cells within the specimen. Downstaging of $\mathrm{T}$ and/ or $\mathrm{N}$ stage of the tumor was defined as partial response. Results: The mean age of the cases was $57.3 \pm 9.8$ years. Preoperative staging revealed T3 tumor in 9 $(39.1 \%)$ and T4 tumor in $14(60.9 \%)$ of cases. In $14(60.9 \%)$ cases there were no lymph node metastases whereas in 9 (39.1\%) cases lymph node involvement was detected. The tumor location was as follows; lower rectum $34.8 \%$, mid-rectum $30.4 \%$, and at upper rectum $34.8 \%$. Sphincter saving resection was performed in $71.4 \%$ of cases. Histopathological complete response was observed in 7(30.4\%) and partial response was observed in 13 (56.5\%) cases. No significant difference was observed between the response to neoadjuvant chemoradiotherapy and tumor localization and sphincter saving resection. Conclusion: Response to neoadjuvant chemoradiotherapy was obtained in majority of the patients. Downstaging was not associated with the rate of sphincter preserving surgery.
\end{abstract}

Key words: Local advanced rectal cancer, neoadjuvant chemoradiotherapy, sphincter protective surgery

\section{Giriş}

Kolorektal kanserler, gastrointestinal sistemin en sık görülen kanserleridir. Görülme sıklığı açısından meme ve akciğer kanserinden sonra üçüncü sıradadır. ${ }^{1}$ Kolorektal kanserlerin yaklaşık 1/3'ü rektum kanseridir. Erken evre rektum tümörlü hastaların tedavisinde küratif tedavinin köşe taşı cerrahidir. İleri tümör evresi ve/veya pozitif lenf nodu olan hastalarda, hastalığın lokal kontrolü ve kürü açısından olumlu sonuçlar elde edebilmek için cerrahi tedaviye radyoterapi (RT) ve kemoterapinin (KT) eklenmesi gerekir. Günümüzde, Doğu Avrupa ülkelerinin çoğunda ve Amerika Birleşik Devletleri'nde, lokal ileri evre rektum kanserinde standart tedavi olarak neoadjuvan kemoradyoterapi (KRT) kullanılmaktadır. ${ }^{2}$ Bizim ülkemizde de benzer bir yaklaşım söz konusudur. Lokal ileri (T3/T4) ve/veya lenf düğümü tutulumu olan rektum kanserli olguların tedavisinde neoadjuvan KRT tercih edilen yöntem haline gelmiștir. Neoadjuvan KRT ile lokal ileri rektum kanserlerinde tümör boyutunda küçülmeye bağlı küratif rezeksiyon ve sfinkter koruyucu cerrahi yaplabilirliğinin arttığl, total mezorektal eksizyona neoadjuvan tedavi eklenmesi ile de daha düşük lokal nüks elde edilebileceği gösterilmiştir. ${ }^{3-5}$ Neoadjuvan tedavi sonrasında olguların \%19'unda patolojik tam yanıt (pTY) sağlanabildiği görülmektedir. ${ }^{6}$

$\mathrm{Bu}$ çalışmada, lokal ileri ve/veya lenf düğümü tutulumu olan rektum kanseri nedeniyle neoadjuvan KRT uygulanan olgularda tümörün evresinde izlenen değişikliklerin ve patolojik yanıt oranlarının belirlenmesi amaçlanmıştır. 


\section{Yöntem}

Tanımlayıcı tipte planlanan bu çalışma

için Mersin Üniversitesi Klinik Etik Kurulundan onay alınmıştır. Mersin Şehir Eğitim ve Araștırma Hastanesi Radyasyon Onkoloji Bölümünde 2017 yılı içerisinde neoadjuvan kemoradyoterapi uygulanmış olan lokal ileri ya da lenf düğümü metastazı olan rektum kanserli 40 olgunun verileri retrospektif olarak değerlendirildiğinde 23 olgunun verilerine ulaşılabildi. Bu olguların 21'ine cerrahi yapıldığı saptandı. Olgular demografik özellikleri, tümör histolojisi, klinik evreleri, uygulanan kemoterapi protokolü, radyoterapi dozları, uygulanan cerrahi yöntem ve sonuçları, patolojik tedavi yanıtları açısından retrospektif olarak değerlendirildi.

Tedavi planlaması sırasında serideki tüm olgulara genel fizik bakı, rektal tuşe, tam kan sayımı, kan biyokimyası, rijit rektosigmoidoskopi, kolonoskopi, tümör biyopsisi, pozitron emisyon tomografisi (PET CT) ve manyetik rezonans (MR) inceleme yapıldı. Tümörün patolojik evrelendirmesi American Joint Commite on Cancer (AJCC) TNM evreleme sistemine göre yapıldı. ${ }^{7}$

Olguların tedavisi, multidisipliner olarak (Cerrahi, Patoloji, Radyasyon Onkolojisi, Tıbbi Onkoloji, Gastroenteroloji ve Radyoloji) tümörün yerleşimi, evresi, yaşı, Dünya Sağlık Örgütü (DSÖ) performans durumu ve yandaş hastalıkları ile birlikte değerlendirilerek planlandı. Çalışmaya üst, orta ve alt rektum yerleşimli, lokal ileri (T3/ T4) ve/ veya lenf dügümü tutulumu olan (evre II-III) olgular dahil edildi.

Rektum anal girimden itibaren sıfır ve 15. cm'ler arasinda kalan barsak segmenti olarak tanımlandl; anal girimden itibaren sıfır ile beș. $\mathrm{cm}$ arasında olan kısım alt rektum, altı ile 10. $\mathrm{cm}$ arasında olan kısım orta rektum, 11 ile 15. $\mathrm{cm}$ arasında olan kısım üst rektum olarak sınıflandırıldı.

Tüm olgulara eşzamanlı KRT protokolü doğrultusunda radyoterapi (RT) ile birlikte $225 \mathrm{mg} / \mathrm{m} 2$ 5-Fluorourasil (5-FU) sürekli infüzyon yöntemiyle, damar yolu problem olanlara ise Kapesitabin $825 \mathrm{mg} / \mathrm{m} 2$ günde iki kez olarak uygulanmıştır.

Radyoterapi planlaması bilgisayarlı tomografi ile elde olunan üç boyutlu anatomik verilere dayanarak, tümör dokusuna maksimum dozu verirken çevre normal dokuya olabilecek en düşük dozu verecek şekilde yapılmıştır. Tümör ve perirektal lenf dügümlerinden oluşan hedef alan sagittal eksende 5'er $\mathrm{cm}$, koronal eksende 3'er $\mathrm{cm}$ ve aksiyal eksende 3 'er $\mathrm{cm}$ güvenlik sınırı bırakılarak belirlendi. Ameliyat öncesi RT yüksek enerjili 15MV X ışını kullanılarak dört alan foton tekniği ile toplam 5040 cGy doz, 1.8 Gy'lik fraksiyonlar halinde, 28 günde uygulanmıştır. Planlanan hedef alanın sınırları: ön-arka alanların lateral kenarları kemik pelvisi $2 \mathrm{~cm}$ güvenlikle geçecek şekilde; üst sınır sakral promontoriumun $1.5 \mathrm{~cm}$ üzerini; alt sınır tümörün $5 \mathrm{~cm}$ altındaki alanı (distal sınırı anal girimden $6 \mathrm{~cm}$ içeride olan tümörler de anüs RT alanına dahil edilmiştir.), lateral alanlarda arka sınır tüm sakrumu, ön sinır T3 hastalıkta simfizis pubisin arkasından, T4 hastalıkta eksternal iliyak lenf dügümlerini de içererek simfizis pubisin önünden geçecek şekilde planlanmıştır (Şekil 1).

Küratif amaçlı cerrahi rezeksiyon KRT bitiminden dört-sekiz hafta sonra yapılmıştır. Alt ve orta rektum tümörlerinde sfinkter korunabilenlerde aşağı anterior rezeksiyon (LAR) ve total mezorektal eksizyon (TME) yapılmış olup sfinkter korunamayan hastalara ise abdominoperineal rezeksiyon (APR) uygulanmıştır. Üst rektum yerleşimli tümörlerde LAR ile birlikte mezorektum tümörün distal sınırının beş $\mathrm{cm}$ altından bölünmüştür. Cerrahi rezeksiyon materyalinin histopatolojik incelemesi Quirke ve ark. ${ }^{8}$ tarafından tanımlanan prensipler çerçevesinde yapılmıştır.

Neoadjuvan KRT'ye yanitın değerlendirmesi ameliyat öncesi evreleme ile patolojik evrenin karşılaştırılması ile yapıldı. Rezeksiyon materyalinde herhangi bir kanser hücresi gözlenmemesi (pT0N0), patolojik tam yanıt (pTY) olarak değerlendirildi. Tümörün T evresindeki gerileme (TG) ve $\mathrm{N}$ evresindeki 
gerileme (NG), kısmi yanıt (KY) olarak değerlendirildi.

Analizler MedCalc istatistik programı kullanılarak yapıldı. Neoadjuvan KRT'ye yanıt ile sfinkter koruyucu cerrahi yapılabilirliği ve alt rektum yerleşimli tümörlerde neoadjuvan tedaviye yanıt ile yapilan ameliyat tipinin karşılaştırılmasında ki-kare testi kullanıldı. p $<0.05$ değeri anlamlı kabul edildi.
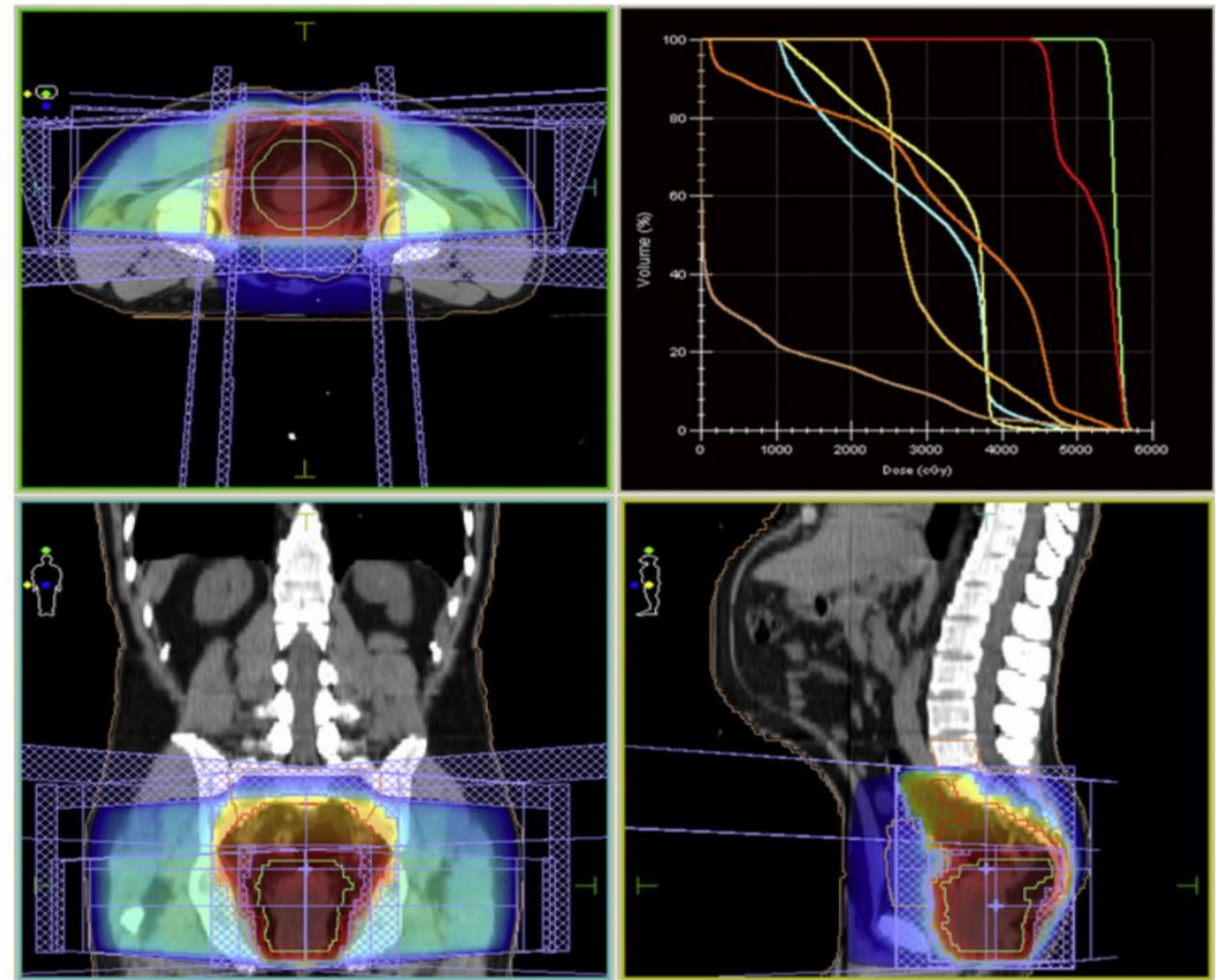

Şekil 1: Rektum Kanserinde Radyoterapi Planlaması

\section{Bulgular}

Olguların ortalama yașı $57.3 \pm 9.8$ olup 4'ü (\%17.4) kadın, 19'u (\%82.6) erkek idi. Tedavi öncesi yapılan radyolojik incelemelerde olguların 9'unda (\%39.1) klinik T3 (cT3), 14'ünde (\%60.9) cT4 tümör saptandı; olguların 14'ünde (\%60.9) lenf düğümü metastazı izlenmezken klinik N0 (cN0) 9 olguda (\%39.1) lenf düğümü metastazı saptandı (cN+). Tümörün yerleşim yeri olguların 8'inde (\%34.8) alt rektum, 7'sinde (\%30.4) orta rektum 8'inde (\%34.8) üst rektum idi (Tablo1).

Neoadjuvan KRT sonrası olguların 7'sinde (\%30.4) pTY (pT0N0), 13'ünde (\%56.5) kısmi yanıt ( $\mathrm{T}$ ve/veya $\mathrm{N}$ evresinde gerileme) izlendi. Olguların 3'ünde (\%13.1) neoadjuvan KRT'ye histopatolojik yanit izlenmedi (Tablo2). 
Neoadjuvan tedavi sonrası cerrahi girişim uygulanan 21 olgu incelendiğinde sfinkter koruyucu cerrahinin olguların 15'ine (\%71.4) yapılabildiği, bu 15 olgunun 5'inin (\%33.3) pTY'lı, 10’unun da (\%66.7) kismı yanıtlı ve yanitsızlardan oluştuğu saptanmıştır. Neoadjuvan tedaviye tam yanıt verenlerde sfinkter koruyucu rezeksiyon oranı \%88.3 iken, bu oranın diğerlerinde \%66.7 olduğu, fakat neoadjuvan tedavi ile sfinkter koruyucu rezeksiyon arasında istatistiksel olarak anlamlı bir iliş̧kinin olmadığı tespit edildi ( $p>0.05$ ) (Tablo 3).

Alt rektum yerleşimli tümörü olan 8 olgu incelendiğinde neoadjuvan tedaviye yanıt (tam yanit, TG/NG) \%75.0 oranında izlendi. Alt rektum tümörlü hastalarda neoadjuvan tedaviye yanit ve sfinkter koruyucu cerrahi arasında istatistiksel olarak anlamlı ilişki saptanmadı ( $p>0.05)$ (Tablo 4).

Tablo 1. Hastaların klinik özellikleri

\begin{tabular}{lll}
\hline Klinik Özellik & $\mathrm{n}$ & $\%$ \\
\hline Cinsiyet & & \\
Kadın & 4 & 17.4 \\
Erkek & 19 & 82.6 \\
\hline Tümör yerleşimi & & \\
\hline Üst rectum & 8 & 34.8 \\
Orta rektum & 7 & 30.4 \\
Alt rektum & 8 & 34.8 \\
\hline Klinik evreleme & & \\
\hline cT3 & 9 & 39.1 \\
cT4 & 14 & 60.9 \\
cN0 & 14 & 60.9 \\
cN+ & 9 & 39.1 \\
\hline
\end{tabular}

Tablo 2. Neoadjuvan tedaviye yanit

\begin{tabular}{lll}
\hline Tedaviye yanit & $\mathrm{n}$ & $\%$ \\
\hline Tam yanit & 7 & 30.4 \\
Kismi yanit (TG ve/ NG) & 13 & 56.5 \\
Yanit yok & 3 & 13.1 \\
\hline
\end{tabular}


Tablo 3. Neoadjuvan tedaviye yanıt ile yapılan ameliyat tipi arasındaki ilişki

\begin{tabular}{|c|c|c|c|c|c|c|}
\hline \multirow{3}{*}{ Neoadjuvan tedaviye yanıt } & \multicolumn{4}{|c|}{ Ameliyat Tipi } & & \\
\hline & \multicolumn{2}{|c|}{$\begin{array}{l}\text { Sfinkter koruyucu } \\
\text { rezeksiyon }\end{array}$} & \multicolumn{2}{|c|}{ Abdominoperineal rezeksiyon } & \multicolumn{2}{|c|}{ Toplam } \\
\hline & $\mathrm{n}$ & $\% *$ & $\mathrm{n}$ & $\% *$ & $\mathrm{n}$ & $\% * *$ \\
\hline TY & 5 & 83.3 & 1 & 16.7 & 6 & 28.6 \\
\hline KY/ Yanit Yok & 10 & 66.7 & 5 & 33.3 & 15 & 71.4 \\
\hline Toplam & 15 & 71.4 & 6 & 28.6 & 21 & 100.0 \\
\hline
\end{tabular}

*Satır yüzdesi, **Sütun yüzdesi, p>0.05

Tablo 4. Alt rektum yerleşimli tümörlerde neoadjuvan tedaviye yanıt ile yapılan ameliyat tipi arasındaki ilişki

\section{Ameliyat tipi}

\begin{tabular}{|c|c|c|c|c|c|c|}
\hline \multirow[t]{2}{*}{$\begin{array}{c}\text { Neoadjuvan KRT'ye } \\
\text { yanit }\end{array}$} & \multicolumn{2}{|c|}{$\begin{array}{l}\text { Sfinkter koruyucu } \\
\text { rezeksiyon }\end{array}$} & \multicolumn{2}{|c|}{$\begin{array}{l}\text { Abdominoperineal } \\
\text { rezeksiyon }\end{array}$} & \multicolumn{2}{|c|}{ Toplam } \\
\hline & $\mathrm{n}$ & $\% *$ & $\mathrm{n}$ & $\% *$ & $\mathrm{n}$ & $\% * *$ \\
\hline Yanit Var & 3 & 50.0 & 3 & 50.0 & 6 & 75.0 \\
\hline Yanit Yok & 1 & 50.0 & 1 & 50.0 & 2 & 25.0 \\
\hline Toplam & 4 & 50.0 & 4 & 50.0 & 8 & 100.0 \\
\hline
\end{tabular}

*Satır yüzdesi, **Sütun yüzdesi, p>0.05

\section{Tartışma}

Günümüzde lokal ileri rektum kanserli olguların tedavisinde temel basamak olan küratif cerrahi rezeksiyonla amaç daha iyi lokal kontrol ve sağkalım sonuçları elde etmektir. Temiz cerrahi sınır elde etmek için geniş cerrahi rezeksiyon uygulanmasına rağmen bazen tümör dokusunun tamamen çıkarılamadığı ve sfinkter fonksiyonunun kaybedildiği görülmektedir. Literatürler incelendiğinde neoadjuvan KRT uygulanan lokal ileri rektum kanserli olgularda histopatolojik tam yanıt izlenenlerde daha iyi lokal kontrol ve sağkalım sonuçları olduğu bildirilmektedir. 9,10

İyi prognoz ve yüksek yaşam kalitesi için klinik evrelemenin doğru şekilde yapılması, en uygun ve yeterli tedavi yönteminin seçilmesi açısından önem taşımaktadır. $\mathrm{Bu}$ amaçla günümüzde endorektal ultrasonografi (ERUS), pelvik MR, endorektal MR kullanıldığında $\mathrm{T}$ ve N evresinde sirasiyla \%85-90 ve \%74-76 doğruluk oranlarına ulaşılabildiği görülmektedir. ${ }^{11}$ Serimizdeki tüm olguların klinik evrelemesi, rijit rektosigmoidoskopi, kolonoskopi, pozitron emisyon tomografisi (PET CT) ve manyetik rezonans (MR) sonuçları değerlendirilerek yapıldı.

Literatürler gözden geçirildiğinde lokal ileri evre rektum kanserli olgularda neoadjuvan KRT sonrasinda olguların \%20'sinde pTY, \%60'ında ise kısmi yanıt (TG ve/veya NG) olduğu gösterilmiştir.6,12-15 Bizim çalışmamızda da neoadjuvan KRT sonrası altısekiz hafta içinde opere edilmiş olan olguların postoperatif patoloji raporları değerlendirildiğinde literatürle uyumlu olarak hastaların 7'sinde (\%30.4) pTY, 13'ünde (\%56.5) patolojik kısmi yanit ( TG ve/veya NG) olduğu izlenmiştir. 
Lokal ileri evre rektum kanserinde preoperatif RT veya KRT uygulanması ile sağlanan tümör evresinde gerileme ile sfinkter koruyucu cerrahi uygulanabilirliğinde artıșı destekleyen çalışmalar mevcuttur. 3,5 Wong ve ark. ${ }^{16}$ tarafından yapılan meta analizde ise neoadjuvan tedaviye bağlı sfinkter koruyucu cerrahi yapılabilirliğinin artmadığ bildirilmiștir. Bujko ve ark. ${ }^{17}$ tarafından yapılan sistematik derlemede neoadjuvan tedavi sonrası tümör küçülmesi ya da tam yanitın, sfinkter koruyucu cerrahi oranında istatistiksel olarak anlamlı artış sağlamadığı gösterilmiştir. Çalışmamızda neoadjuvan tedavi sonrası cerrahi girişim uygulanan 21 olgu incelendiğinde sfinkter koruyucu cerrahinin olgularin 15'ine (\%71.4) yapılabildiği ancak neoadjuvan tedaviye yanıt ile sfinkter koruyucu cerrahi arasinda istatistiksel olarak anlamlı bir ilişki olmadığ saptanmıştır ( $p>0.05)$. Olgu sayısının az olması bu çalışmanın zayıf noktası olduğu göz önünde bulundurulduğunda neoadjuvan tedaviye yanıt ile sfinkter koruyucu cerrahi arasında net bir ilişki kurmak için daha geniş olgu içeren çalışmalara gereksinim olduğu kanısındayız.

Sfinkter koruyucu cerrahi yapılabilirliği ile ilişkili en önemli etmenler cerrahi teknik, onkolojik prensiplerin uygulanabilirliği ve tümörün yerleşim yeridir. Neoadjuvan KRT sonrası tümörün boyutlarında küçülme olmasına karşın tümörün alt sınırı ile anal girim arasındaki uzaklık değişmeyebilir. Ayrıca birçok cerrah için distal cerrahi sınırın $1 \mathrm{~cm}$ 'in altında olması (sıklıkla önerilen 1-2 cm'dir) endişe verici bir onkolojik sonuçtur. Polonya çalışmasında neoadjuvan RT/ KRT uygulanan rektum kanserli olguların yaklaşık \%10'unda beș mm'nin üzerinde (en fazla $18 \mathrm{~mm}$ ) distal intramural yayılım olduğu gösterilmiștir.18 Benzer şekilde Bozzetti ve ark. ${ }^{19}$ neoadjuvan RT uygulanan 59 olguyu içeren çalışmalarında olguların \%20'sinde distal intramural yayılım olduğunu (ortalama $4.3 \mathrm{~mm}$ ) bildirmişlerdir

Neoadjuvan tedaviye tam yanit veren olgulara nasıl yaklaşılacağı son yıllarda tartışma konusu olmaktadır. Seçilmiş olgularda cerrahi tedavi yapmadan "bekle gör" yöntemini uygulayanların yanısıra ${ }^{20}$, bu olgularda lokal eksizyonu öneren çalışmalar da mevcuttur. ${ }^{21,22}$ Olgularımızdan, histopatolojik tam yanit elde edilenlere cerrahi uygulanmıştır. Biz tam ya da kısmi yanit alınan hastalarda cerrahi yaklaşımın değiştirilmemesi ya da cerrahiden vazgeçilmemesi gerektiği kanısındayız. Öncelikle fizik bakl, rektal tuşe, endoskopi, biyopsi, ERUS, MR ve PET-BT tümör yanıtını belirlemede etkin yöntemler değildir. $\mathrm{Bu}$ yöntemlerle saptanan klinik tam yanıtın patolojik tam yanıt anlamına geldiğini söylemek günümüz koşullarında olanaksızdır.23-26 Ayrıca, tümörün rektum duvarından eradike edilmiş olmasının mezorektumda rezidü kanser olmadığı anlamına gelmediği çok sayıda çalışma ile gösterilmiştir. 27-29 Son olarak da neoadjuvan KRT'den sonra klinik olarak tam yanıt alındığı düşünülen ve cerrahi uygulanmadan izlenen hastalarda yüksek oranda lokal nüks ve kötü sağkalım sonuçları olduğu gösterilmiştir. ${ }^{30}$

Sonuç olarak çalışmamızda neoadjuvan KRT ile olguların büyük bir kısmında tümörde boyut ve/ veya evre gerilemesi sağlandığı, ancak bu gerilemenin sfinkter koruyucu cerrahiye katkısının olmadığı görülmektedir. Olgu sayısının az olması nedeniyle neoadjuvan tedaviye yanıt ile sfinkter koruyucu cerrahi arasinda net bir sonuca varmak için daha geniş olgu içeren çalışmalara gereksinim olduğu kanaatindeyiz.

\section{Kaynaklar}

1. Cohen AM. Colorectal rumors. In: Morris PJ, Wood WC, Malt RA Eds. The Oxford textbook of Surgery, 2nd Ed.,Oxford: Oxford University Press 2000:1471-1511.

2. Madoff RD. Chemoradiotherapy for rectal cancer ? when, why and how? N Engl J Med 2004; 351:1790-2.

3. Sauer R, Becker H, Hohenberger W, Rödel C, Wittekind C, Fietkau R, Martus P, Tschmelitsch J, Hager E, Hess CF, Karstens JH, Liersch T, Schmidberger $H$, Raab $R$, German Rectal 
Cancer Study Group. Preoperative versus postoperative chemoradiotherapy for rectal cancer. $N$ Engl J Med 2004;351(17):17311740.

4. Rahbari NN, Elbers $\mathrm{H}$, Askoxylakis V, Motschall E, Bork U, Büchler MW, Weitz J, Koch M. Neoadjuvant radiotherapy for rectal cancer: Meta-analysis of randomized controlled trials. Ann Surg Oncol 2013;20(13):4169-4182.

5. Wagman R, Minsky BD, Cohen AM, Guillem JG, Paty PP. Sphincter preservation in rectal cancer with preoperative radiation therapy and coloanal anastomosis: Long term followup. Int J Radiat Oncol Biol Phys 1998;42(1):5157.

6. Das P, Skibber JM, Rodriguez-Bigas MA, Feig BW, Chang GJ, Wolff RA, Eng C, Krishnan S, Janjan NA, Crane CH. Predictors of tumor response and downstaging in patients who receive preoperative chemoradiation for rectal cancer. Cancer 2007;109:1750-1755.

7. Edge SB, Byrd DR, Compton CC, Fritz AG, Greene FL, Trotti A, editors. AJCC cancer staging manual (7th ed). New York, NY: Springer; 2010

8. Quirke P, Durdey P, Dixon MF, Williams NS. Local recurrence of rectal adenocarcinoma due to inadequate surgical resection. Histopathological study of lateral tumour spread and surgical excision. Lancet 1986;2:996-999.

9. Biondo S, Navarro M, Marti-Rague J, Arriola E, Pares D, Del Rio C, Cambray M, Novell V. Response to neoadjuvant therapy for rectal cancer: Influence on long-term results. Colorectal Dis 2005;7:472-479.

10. Devine RM, Dozois RR. Surgical management of locally advanced adenocarcinoma of the rectum. World J Surg 1992;16:486-489.

11. Halefoglu AM, Yıldırım S, Avlanmıs O, Sakız D, Baykan A. Endorectal ultrasonography versus phased-array magnetic resonance imaging for preoperative staging of rectal cancer. World J Gastroenterol 2008;14:3504-
3510.

12. Collette L, Bosset J-F, den Dulk M, Nguyen F, Mineur L, Maingon P, Radosevic-Jelic L, Piérart M, Calaiset G. Patients with curative resection of cT3-4 rectal cancer after preoperative radiotherapy or radiochemotherapy: Does anybody benefit from adjuvant fluorouracil- based chemotherapy? A trial of the European Organisation for Research and Treatment of Cancer Radiation Oncology Group. J Clin Oncol 2007;25:4379-4386.

13. Park IJ, You YN, Agarwal A, Skibber JM, Rodriguez-Bigas MA, Eng C, Feig BW, Das P, Krishnan S, Crane CH, Hu CY, George J. Changet GJ. Neoadjuvant treatment response as an early response indicator for patients with rectal cancer. J Clin Oncol 2012;30:17701776.

14. Silberfein EJ, Kattepogu KM, Hu CY, Skibber JM, Rodriguez-Bigas MA, Feig B, Das P, Krishnan S, Crane C, Kopetz S, Eng C, Chang GJ. Long-term survival and recurrence outcomes following surgery for distal rectal cancer. Ann Surg Oncol 2010;17:2863-2869.

15. Smith KD, Tan D, Das P, Chang GJ, Kattepogu K, Feig BW, Skibber JM, RodriguezBigas MA. Clinical significance of acellular mucin in rectal adenocarcinoma patients with a pathologic complete response to preoperative chemoradiation. Ann Surg 2010;251:261-264.

16. Wong RK, Tandan V, De Silva S, Figueredo A. Preoperative radiotherapy and curative surgery for the management of localized rectal carcinoma. Cochrane Database Syst Rev 2007:CD002102.

17. Bujko K, Kepka L, Michalski W, Nowacki MP. Does rectal cancer shrinkage induced by preoperative radio (chemo) therapy increase the likelihood of anterior resection? A systematic review of randomised trials. Radiother Oncol 2006;80:4-12.

18. Bozzetti F, Baratti D, Andreola S, Zucali R, Schiavo M, P Spinelli, Gronchi A, Bertario L, Mariani L, Gennari L. Preoperative radiation 
therapy for patients with T2-T3 carcinoma of the middle-to-lower rectum. Cancer 1999;86:398-404.

19. Habr-Gama A, Perez RO, Nadalin W, Sabbaga J, Ribeiro U Jr, Silva e Sousa AH Jr, Campos FG, Kiss DR, Gama-Rodrigues J. Operative versus nonoperative treatment for stage 0 distal rectal cancer following chemoradiation therapy: Long-term results. Ann Surg 2004;240:711-717.

20. Schell SR, Zlotecki RA, Mendenhall WM, Marsh RW, Vauthey JN, Copeland EM 3rd. Transanal excision of locally advanced rectal cancers downstaged using neoadjuvant chemoradiotherapy. J Am Coll Surg 2002;194:584-590.

21. Kim CJ, Yeatman TJ, Coppola D, Trotti A, Williams B, Barthel JS, Dinwoodie W, Karl RC, Marcet J Local excision of T2 and T3 rectal cancers after down- staging chemoradiation. Ann Surg 2001;234:352-358.

22. Habr-Gama A, de Souza PM, Ribeiro U Jr, Nadalin W, Gansl R, Sousa AH Jr, Campos FG, Gama-Rodrigues J. Low rectal cancer: Impact of radiation and chemotherapy on surgical treatment. Dis Colon Rectum 1998;41:10871096.

23. Guillem JG, Chessin DB, Shia J, Moore HG, Mazumdar M, Bernard B, Paty PB, Saltz L, Minsky BD, Weiser MR, Temple LKF, Cohen AM,Wong WD. Clinical examination following preoperative chemoradiation for rectal cancer is not a reliable surrogate end point. J Clin Oncol 2005;23:3475-3479.

24. Chen CC, Lee RC, Lin JK, Wang LW, Yang $\mathrm{SH}$. How accurate is magnetic resonance imaging in restaging rectal cancer in patients receiving preoperative combined chemoradiotherapy? Dis Colon Rectum 2005;48:722-7228.

25. Capirci C, Rubello D, Chierichetti F, Crepaldi G, Carpi A, Nicolini A, Mandoliti G, Polico C. Re- staging after neoadjuvant chemoradiotherapy for rectal adenocarcinoma: Role of F18-FDG PET. Biomed Pharmacother 2004;58:451-457.

26. Meterissian S, Skibber J, Rich T, Roubein L, Ajani J, Cleary K, Ota DM. Patterns of residual disease after preoperative chemoradiation in ultrasound T3 rectal carcinoma. Ann Surg Oncol 1994;1:111-116.

27. Zmora O, Dasilva GM, Gurland B, Raphael Pfeffer; Moshe Koller; Juan J. Nogueras; Steven D. Wexner. Does rectal wall tumor eradication with preoperative chemoradiation permit a change in the operative strategy? Dis Colon Rectum 2004;47:1607-1612.

28. Stipa F, Zernecke A, Moore HG, Minsky BD, Wong WD, Weiser M, Paty PB, Shia J, Guillem JG. Residual mesorectal lymph node involvement following neoadjuvant combinedmodality therapy: rationale for radical resection? Ann Surg Oncol 2004;11:187-191.

29. Nakagawa WT, Rossi BM, de O Ferreira F, Ferrigno R, David Filho WJ, Nishimoto IN, Vieira RA, Lopes A. Chemoradiation instead of surgery to treat mid and low rectal tumors: Is it safe? Ann Surg Oncol 2002;9:568-573.

30. Bo Young Oh, Jung Wook Huh, Woo Yong Lee, Yoon Ah Park, Yong Beom Cho, Seong Hyeon Yun, Hee Cheol Kim, Ho-Kyung Chun. Are We Predicting Disease Progress of the Rectal Cancer Patients without Surgery after Neoadjuvant Chemoradiotherapy? Cancer Res Treat 2018;50(3):634-645. 